\title{
AS ORIGENS DOS MARDI GRAS INDIANS DE NOVA ORLEANS EM CONTEXTO ATLÂNTICO
}

DEWULF, Jeroen. From the Kingdom of Kongo to Congo Square: Kongo Dances and the Origins of the Mardi Gras Indians. Lafayette: University of Louisiana at Lafayette Press, 2017. 242 p.

$E_{\mathrm{m}}$ seu último livro, Jeroen Dewulf, professor da Universidade da Califórnia em Berkeley, pretende compreender as origens dos Mardi Gras Indians, performance negra central no carnaval da cidade de Nova Orleans, Luisiana, EUA. Sua tese central fica evidenciada logo no título do livro: Do Reino do Kongo, na África Central, à Congo Square, em Nova Orleans. Ou seja, as Kongo Dances (danças do Congo) - performances negras descritas nas fontes desde o final do século XVIII - podem ser rastreadas até às danças de guerra simuladas no antigo Reino do Congo, que ficava a noroeste da atual Angola, nos séculos XVI e XVII, e seriam a base para reinvenções até a criação dos Mardi Gras Indians da atualidade. ${ }^{1}$ Essas reinvenções e adaptações respondiam

1 Não confundir o antigo Reino do Congo - que a bibliografia anglófona grifa Kongo -, localizado a noroeste da atual Angola, com o atual país Congo. Sempre que me referir a Congo nesta resenha quero dizer o Reino do Congo. aos desafios sociais que os africanos e seus descendentes enfrentavam nas Américas. Performances congolesas, portanto, devem ser entendidas como atos entre a tradição e a adaptação. "Eram mais tradições 'inventivas' do que 'inventadas"' (p. 17).

Tal hipótese, que pode parecer pouco impactante para a historiografia das congadas, maracatus ou cucumbis no Brasil, por exemplo, tem um peso grande para a historiografia associada aos grupos de negros fantasiados de "índios" que desfilam no carnaval de Nova Orleans, lá conhecido como Mardi Gras. Conforme aponta Dewulf, é comum e amplamente aceita a narrativa de que essa performance teria se iniciado com os Wild West shows de Buffalo Bill, em finais do século XIX. O argumento de Dewulf segue proposições de pesquisadores como Samuel Kinser, Reid Mitchel e Ned Sublette: as danças dos índios do Mardi Gras "estavam por um longo tempo em gestação" ou teriam 
sido cultivadas "muito tempo dentro da comunidade negra" (p. 13). A pesquisa de fôlego encampada por Dewulf logra comprovar o que era apenas uma suposição de pesquisadores atentos. No livro, o autor afirma que Buffalo Bill e seu Wild West Show não iniciaram a tradição dos indios no Mardi Gras - mesmo que a tenham influenciado em certa medida. Na verdade, seus shows teriam "reforçado e estereotipado uma prática negra muito mais antiga de se vestir com adereços de penas na cabeça em ocasiões festivas" (p. 13).

Os "índios negros" do Mardi Gras representariam "uma variante específica de um fenômeno muito mais amplo, que tem sido observado em muitas outras partes das Américas" (p. 13), como outros pesquisadores já demonstraram comparando com tradições dos carnavais do Caribe. A diferença e a contribuição mais significativas do livro de Dewulf é justamente a ampliação do escopo da pesquisa, numa análise comparativa que inclui a América de língua espanhola, o Brasil e a África, além do Caribe e dos EUA. Dessa maneira, ele busca construir uma nova teoria "sobre a origem e os sentidos dos Mardi Gras Indians" (p. 13).

Por conseguinte, Dewulf busca se afastar do que ele chama de tendência à "nostalgia seletiva", que liga performances e cultura musical negras "a uma terra-mãe africana intocada e virgem" (p. 19). Pois a "mistura sincrética" teria começado ainda em solo africano, por isso, é preciso entender esse processo a partir de fontes históricas dos séculos XVI e XVII. Para tanto, é necessário utilizar fontes em outros idiomas que não apenas o inglês, entender a Luisiana como parte da diáspora congolesa, e pensá-la em conexão com outras experiências americanas. São esses argumentos que justificam o percurso longo e de fôlego trilhado no livro, dividido em oito capítulos: o autor parte da Congo Square, com suas Kongo Dances, e retorna para o sangamento no Reino do Kongo; em seguida acompanha sua difusão por São Tomé e Príncipe, América Latina, Haiti e o Caribe; e retorna para a Congo Square, analisando sua relação com o Carnaval, sua música e os grupos de Black Indians de Nova Orleans. Segundo o autor, as Kongo Dances são mais do que apenas danças, elas contam uma história: "é essa história que provê a chave para desvelar os segredos dos Mardi Gras Indians" (p. 20).

No primeiro capítulo, o autor faz um histórico da colonização da cidade de Nova Orleans e da presença negra, iniciando no século XVI. Baseado na historiografia, caracteriza o tráfico de africanos para a região sob domínio francês e depois espanhol, apontando a predominância de escravos vindos da região do antigo reino do Congo. Na primeira década do século XIX, a região foi comprada pelos EUA, e viveu um boom da plantação de açúcar e algodão, junto com a chegada de franceses refugiados de São Domingos, com número significativo de escravos e negros li- 
vres - a maioria também seria oriunda da região do Kongo.

Dewulf utiliza como fontes jornais, guias de viagem, legislação, mas principalmente viajantes e memorialistas para apresentar os tipos de performances que eram comuns na Congo Square de Nova Orleans na primeira metade do século XIX. Através dessas fontes, ele descreve as danças e demonstra que já estavam presentes no cotidiano da cidade décadas antes do nascimento de Buffalo Bill. Relatos de viajantes e artigos de jornais descrevem performances de membros de nação Congo, com desfile, rei, coroa, guizos nos pés, plumas nas cabeças, chifres sendo tocados, sinos badalados. Os jornais descrevem essas danças acontecendo também na zona rural, extrapolando $\mathrm{a}$ área urbana de Nova Orleans.

É importante frisar que, em muitos momentos, o autor se priva de descrever com a minúcia necessária o caráter das fontes utilizadas. Assim, não sabemos ao certo quem são os jornalistas que produzem os artigos sobre as danças. Buscando apresentar como tais performances foram descritas nos jornais e favorecer a descrição de elementos que ajudarão na análise comparativa dos próximos capítulos pode levar os leitores a entender essas fontes de forma pouco complexa, já que sua especificidade não é debatida, e, portanto, a análise não atinge a história social desses sujeitos.

O mesmo acontece no capítulo II, sobre os sangamentos no Reino do Congo. Dewulf utiliza viajantes e missionários como fontes principais para caracterizá-los, porém não dedica tempo suficiente para a crítica dessas fontes. Mesmo que isso possa fragilizar o capítulo, a hipótese principal é demonstrada e consiste em que podemos encontrar muitos paralelos entre sangamento e danças do Congo nas Américas.

Os sangamentos seriam a "mais importante tradição performática do Reino do Kongo" (p. 21): uma dança de guerra simulada que teria um papel importante na estrutura política do reino, especialmente em momentos de transição de poder - a sucessão do rei, o manicongo. $\mathrm{O}$ autor utiliza fontes de missionários e viajantes e a já consolidada historiografia para apresentar o processo de disputa política interna no Reino do Congo no início do século XVI e sua relação com a presença portuguesa $\mathrm{e}$ especialmente o catolicismo.

Nesse contexto, e com o crescimento da influência política dos portugueses na região, os sangamentos assumem um caráter de ferramenta diplomática para o reino. Ao longo dos séculos XVI e XVII, muitos elementos culturais europeus haviam sido incorporados à cultura performática congolesa: procissões, irmandades e liturgia católicas, músicas devocionais, instrumentos musicais, e a partir do declínio político do Congo após a derrota para os portugueses na batalha de Ambuíla, em 1665, a "diáspora congolesa", formada pelas vítimas da guerra, vendidas como escravos para os traficantes europeus, teria levado um 
conjunto de tradições performáticas para diversos pontos das Américas, e teriam sobrevivido sob o nome de Kongo Dances nos EUA e outros nomes alhures (p. 41).

Elementos performáticos tradicionais da cultura congolesa estariam presentes no Brasil, em Cuba, no Haiti e também em Nova Orleans. As danças do Congo são, portanto, claramente relacionáveis com os sangamentos: masculina, gestos agressivos, giros, pulos altos, aclamações a um rei, cabeças enfeitadas de plumas, cintos com sinos, tudo isso simulando uma dança de guerra. Entretanto, não fica evidente para o leitor quem são os africanos considerados congoleses: os que embarcam nos portos da região do Reino do Congo, pessoas lá nascidas, ou mesmo qual o contato da cultura congolesa com as demais tradições da região da África Central. Assim, Reino do Congo e cultura congolesa aparecem muitas vezes de modo genérico, de quem pressupõe uma hegemonia e homogeneidade ao usá-los.

Os primeiros lugares que, já no século XV e início do XVI, haviam recebido africanos escravizados da região do Congo foram as ilhas atlânticas de São Tomé e Príncipe. Ao longo do capítulo 3, o autor apresenta as irmandades religiosas católicas e sua importância na formação de identidades e demonstra como danças ligadas às tradições congolesas já eram ali praticadas no século XVI. O capítulo aponta indícios importantes para o argumento central do autor, de que membros da diáspora congolesa iriam impingir sua marca nas performances e tradições culturais nas duas margens do Atlântico, associando tradições do antigo Congo com elementos ibéricos católicos.

Nos capítulos seguintes, Dewulf apresenta o papel de destaque das irmandades religiosas católicas como espaço de florescimento das performances culturais congolesas nas Américas, fora os EUA. Suas características são muito semelhantes em todas essas regiões: rei eleito e coroado pelos membros da irmandade, trono, sombrinhas, chifres sendo tocados, homens armados com porretes, fantasias de diabos, "índios selvagens", guizos, tambores e presença nas ruas nos dias de Reis (Epifania) e de Corpus Christi, principalmente. Esses elementos comuns não seriam coincidência, mas "indicam que deve ter havido um substrato afro-ibérico em performances culturais negras nas Américas. Esse substrato só pode ser explicado com referência à história antiga da escravidão nas Américas" (p. 111). Ele conclui que os membros da nação Congo ocuparam papel de "lideranças na formação de irmandades e na disseminação de seus rituais por toda América” (p. 122).

O Brasil é um caso importante para a comparação e argumentação do autor. Ele apresenta relatos de viajantes para demonstrar a importância de escravizados do Congo no Brasil e a presença significativa de fontes sobre irmandades e congadas desde o século XVI até o XX. 
Entretanto, há uma ausência marcante nesses capítulos: o autor praticamente não usa a historiografia sobre escravidão e sobre as formas de resistência - vasta e consolidada para toda América, desde os EUA até a Argentina - como ferramenta interpretativa na elaboração de sua análise. Isso limita o entendimento dos sentidos de cada performance em determinado contexto histórico.

Dewulf recorre a viajantes, folcloristas e trabalhos acadêmicos para apontar as semelhanças entre congadas, reisados, cucumbis e maracatus com outras performances negras que utilizam indumentárias de plumas e são associadas aos "índios". É interessante como o autor demonstra a construção de uma associação entre as performances de Black Indians com a imagem do índio selvagem, bárbaro, demoníaco inimigo da civilização. Dewulf argumenta que a presença de homens negros vestidos de "índios selvagens" e diabos remontaria às celebrações do dia de Reis e Corpus Christi na Europa.

Entretanto, a ausência de um maior esforço em direção à história social e política impede o autor de avançar na compreensão dos significados dessas práticas para os próprios sujeitos. Um caso exemplar se refere ao uso das fontes iconográficas. Em torno de três dezenas de imagens compõem a obra. Em alguns casos são importantes para compreender com mais facilidade o argumento do autor. Entretanto, a maioria delas aparecem apenas como ilustrações, sem que sejam exploradas como fonte relevante de análise.

Uma fotografia de 1907, por exemplo, utilizada apenas ilustrativamente, induz a uma interpretação equivocada do Carnaval carioca: "Irmandade com 'índios negros' se preparando para um préstito no Rio de Janeiro. Fotógrafo desconhecido. Originalmente publicado em $\mathrm{OMa}$ lho (23 de março de 1907)" (p. 79). Essa imagem - que por acaso estudei em minha tese de doutorado - possui legenda distinta na edição citada da revista: "Grupo Carnavalesco Coração de Ouro à saída de sua sede à Travessa 11 de Maio. Fotografia tirada pelo amador Luiz Martins Corrêa, no domingo de Carnaval". ${ }^{2}$ A foto registra um cordão carnavalesco com quatro índios à frente (homens negros), seguidos por uma pessoa fantasiada provavelmente de Rei dos Diabos, três estandartes (onde no primeiro se vê o coração dourado que dá nome ao grupo). Não é possível visualizarmos os instrumentos musicais, mas tudo indica que eram acompanhados por um grupo de "pancadaria" (percussivo).

Contudo, isso não inviabiliza a argumentação central de Dewulf nesses capítulos: tradições congolesas foram levadas através do Atlântico e floresceram no contexto das associações de ajuda mútua, como

2 Eric Brasil, "Carnavais atlânticos: cidadania e cultura negra no pós-abolição do Rio de Janeiro, Brasil e Porto de Espanha, Trinidad (1838-1920)" (Tese de Doutorado, Universidade Federal Fluminense, 2016). 
eram as irmandades, que elegiam seus reis a partir das tradições reais congolesas. As irmandades foram responsáveis por incorporar tais tradições em uma variedade de rituais performáticos católicos que tornaram "essas danças intrinsecamente violentas, com espadas e outras armas aceitáveis pelas autoridades locais, e evitavam suspeitas de tramas" (pp. 97-98). Danças do Congo (sangamentos) comumente tinham lugar em feriados católicos, como o dia de Reis e Corpus Christi. Essas performances foram, ao longo do século XIX, sendo incorporadas aos dias de Carnaval.

E com isso, o autor retorna para o território da cidade de Nova Orleans nos capítulos sexto e sétimo, "From Congo Square to Mardi Gras" e "Tangos in New Orleans". Aqui ele argumenta que, em Nova Orleans, as associações de ajuda mútua tiveram uma importância acentuada para a comunidade negra, que precederia a abolição da escravidão. Nesse sentido, a Congo Square teve para a comunidade escrava da cidade uma profunda importância, que ultrapassava o entretenimento. A praça possibilitava o encontro da comunidade escrava e negra para escolher seus líderes, organizar grupos para ajuda mútua, honrar seus mortos e transmitir sua herança cultural para os mais jovens. Essas características se aplicam também aos grupos de Mardi Gras Indians no século XX. Pesquisas dos anos 1940 mostram que esses grupos estavam complexamente organizados como socieda- des secretas e de ajuda mútua. Assim como em Cuba, eles teriam se organizado em torno de identidades de nações.

Dewulf buscou demonstrar a presença dos elementos de tradições congolesas nos carnavais de Nova Orleans, especialmente nas duas práticas mais reconhecidamente associadas com a comunidade negra no Carnaval: a coroação do rei Zulu, Krewe of Zulu, e o Mardi Gras Indians. Mas, ao mesmo tempo, ambas teriam se construído a partir de fantasias populares que estiveram ligadas no passado às irmandades negras e à cultura católica de procissões da cidade francesa. Conclui-se que, após apresentar todas as semelhanças, é possível afirmar que os Black Indians de Nova Orleans teriam a mesma origem afro-ibérica daqueles do Brasil, Cuba, Trinidad e outros lugares das Américas que floresceram na cultura católica de procissões (p. 185).

Mas, então, por que negros se tornaram tão apegados ao costume de mascarar-se como índios e por que membros da nação Congo, em particular, abraçaram essa tradição? A resposta nos levará de volta ao Reino do Congo.

Mais do que assumir a imagem do índio americano como símbolo de participação da nação, é preciso entender essa prática através da própria tradição congolesa de se fantasiar com penas na cabeça. Guerreiros congoleses usavam assim tais penas durante os sangamentos. $\mathrm{O}$ autor busca evidenciar 
sua tese com fontes do século XVI, fotos e artefatos mais recentes, para demonstrar como era comum no Reino do Congo a utilização de indumentárias de penas entre guerreiros, feiticeiros e músicos.

Tanto os diabinhos, as congadas e cucumbis, quanto os Mardi Gras Indians representam o "comportamento cultural da comunidade congolesa [que pode ser] caracterizado por uma marcante criatividade em reinventar tradições sob circunstâncias adversas, e muito do que parecia humilhante e ridículo se visto de fora era profundamente significativo para a própria comunidade" ( $\mathrm{p}$. 193). Tanto o Krewe of Zulu quanto os Mardi Gras Indians exibiam uma "transcrição oculta", "significando que os sujeitos compartilhavam um determinado conhecimento e transmitiam uma determinada mensagem que permanecia escondida para os de fora" (p. 193): mensagem de reinvenção, flexibilidade e criatividade da comunidade negra no sentido de continuar a adaptar a tradição em circunstâncias hostis, um processo de reinvenção que, no entanto, teria começado ainda no continente africano. Seria essa natureza sincrética de sua cultura natal e sua abertura para a constante reinvenção o elemento-chave que permitiu aos congoleses terem essa tremenda influência na música e dança contemporâneas, inclusive no jazz. O que não quer dizer que seus reinventores do século XIX tivessem plena consciência de seus significados originais. Nas palavras do autor, eles o fizeram porque elementos das antigas estruturas das irmandades sobreviveram nas sociedades negras após a abolição, continuaram ligados a rituais que formaram vínculos profundos entre seus ancestrais, assim como continuaram apoiando-se na ajuda mútua.

O livro de Dewulf atinge seus objetivos e o trabalho representa uma contribuição importante para qualquer pesquisador interessado em refletir sobre a diáspora africana nas Américas. Além disso, consegue comprovar suspeitas de vários pesquisadores sobre os sentidos dos grupos de índios presentes nas culturas negras das mais variadas regiões das Américas. Essas performances estão profundamente conectadas com as memórias da África, com a experiência do tráfico e da escravidão, e representam formas de ampliar espaços de autonomia, fortalecer e alargar identidades e conquistar melhoria de vida.

Com pesquisa de fôlego, trilhando caminhos entre fontes de São Tomé, Brasil, do Caribe e da América hispânica, apoiado em ampla e recente bibliografia dessas regiões, Dewulf nos mostra um quadro bastante completo, vibrante e conectado das performances negras reinventadas por "membros da comunidade congolesa", desde o Reino do Congo até o Mardi Gras de Nova Orleans. Um exercício de história comparada que deixa poucas dúvidas no que tange seu objetivo principal: compreender e explicar as origens dos Mardi Gras Indians. 
Assim, todas as comparações realizadas a partir de fontes primárias e de bibliografia especializada são pertinentes e eficazes para a elaboração do argumento de maneira didática e coerente. Entretanto, ao concluir a obra, um leitor interessado em história social, como eu, fica com a sensação de que um universo de sentidos e significados ainda permanece envolto em mistério. $\mathrm{O}$ autor, por todo o livro, evita avançar nas análises sobre a vida material dos criadores das performances estudadas. Os contextos políticos, sociais e econômicos passam muito ao largo das comparações das tradições que investiga.

Se os membros da comunidade negra de Nova Orleans deliberadamente escolhem manter certas performances, mesmo sem ter plena consciência dos sentidos para seus antepassados, caberia ao historiador investigar os sentidos coevos, e para isso seria fundamental a análise cuidadosa da vida material e inserção política desses sujeitos: suas profissões e relações de trabalho, relações com autoridades, local de moradia, seus acessos aos direitos básicos da cidadania, o que só é possível alcançar com a análise do contexto histórico em que estão inseridos.

Essa é uma lacuna que não diminui a importância do livro, da pesquisa e das conclusões produzidas por Dewulf para os estudos sobre as diásporas negras nas Américas. Pelo contrário, From the Kingdom of Kongo to Congo Square abre um novo rol de possibilidades interpretativas para pesquisas que busquem outras abordagens epistemológicas para as performances negras nas Américas: realizar pesquisas de histórias conectadas e transnacionais com qualidade e rigor, sem cair na tentação de apenas elaborar uma lista de semelhanças. Também nos mostra para onde avançar a partir daí: história social da cultura negra nas Américas numa perspectiva transnacional.

Eric Brasil profericbrasil@unilab.edu.br Universidade da Integração Internacional da Lusofonia Afro-Brasileira (Unilab) campus dos Malês 